\title{
Anatomy of the Red Panda (Ailurus fulgens)
}

\author{
Modesta Makungu (Corresponding Author)
}

Department of Veterinary Surgery and Theriogenology, College of Veterinary Medicine and Biomedical Sciences, Sokoine University of Agriculture, P O Box 3020, Morogoro, Tanzania.

Email: modesta_makungu@yahoo.com; makunguliku@sua.ac.tz

Received: September 21, 2018 Accepted: October 19, 2018

doi:10.5296/jbls.v10i1.13677 URL: https://doi.org/10.5296/jbls.v10i1.13677

\begin{abstract}
The red panda (Ailurus fulgens) is an endangered species primarily distributed in the southern China and Himalayas. It lives in mountain forests with bamboo understory. This review outlines the normal anatomy of the red panda in terms of its musculoskeletal system, respiratory system, circulatory system, digestive system and urogenital system. Knowledge of the normal anatomy of individual animal species is important for species identification and accurate interpretation and diagnosis of diseases.
\end{abstract}

Keywords: anatomy, red panda

\section{Introduction}

The red panda (Ailurus fulgens) (Figure 1) is classified as an endangered species by the International Union for Conservation of Nature and Natural Resources (IUCN, 2018). It belongs to order; Carnivora, family; Ailuridae, and genus; Ailurus (Wei and Zhang, 2009; IUCN, 2018). The red panda is the only living species of the family Ailuridae and genus Ailurus and is closely related to mustelids, procyonids and skunks (Wei and Zhang, 2009; Groves, 2011). 


\section{$\triangle$ Macrothink}

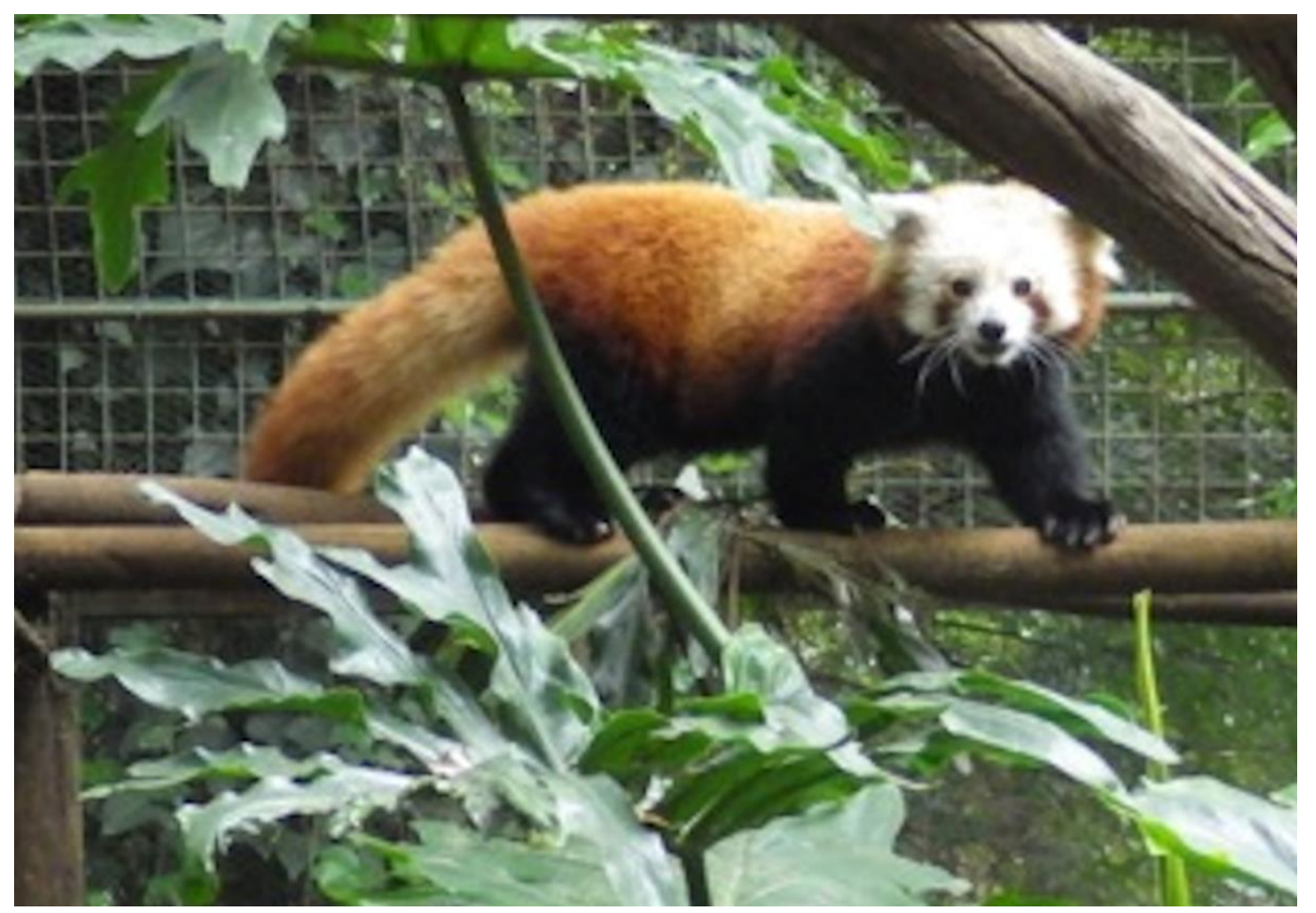

Figure 1. A photograph of an adult red panda (Ailurus fulgens fulgens)

It is primarily distributed in India, Burma, China, Bhutan and Nepal (Roberts and Gittleman, 1984; Ghose and Dutta, 2011). The red panda is mainly an arboreal animal living in mountain forests with bamboo understory at an altitude of 1500 to $4800 \mathrm{~m}$ (Srivastav et al., 2009). It is found in multiple vegetation types like deciduous forests, coniferous forests, evergreen forests, deciduous and coniferous mixed forests and evergreen and deciduous broad-leaf forests (Wei and Zhang, 2011). Red pandas habitat contains tree stumps, high density of shrubs, and fallen logs that provide an easy access to bamboo leaves (Wei and Zhang, 2011). Apart from spending most of their time in trees, red pandas prefer other elevated surfaces such as rocks (Roberts and Gittleman, 1984; Pradhan et al., 2001). Trees provide red pandas with sites for sleeping, nesting, resting and escaping from predators (Roberts and Gittleman, 1984; Srivastav et al., 2009; Eriksson et al., 2010).

The head and body length of red pandas ranges from 56 to $62.5 \mathrm{~cm}$ (Roberts and Gittleman, 1984). The tail length ranges from 37 to $47.2 \mathrm{~cm}$ (Roberts and Gittleman, 1984). Wild red pandas weigh between four to five $\mathrm{kg}$ (Preece, 2011). The mean weight of adult females and males in captivity is $4.9 \mathrm{~kg}$ (range: $4.2-6.0 \mathrm{~kg}$ ) and $5 \mathrm{~kg}$ (range: $3.7-6.2 \mathrm{~kg}$ ), respectively, (Roberts and Gittleman, 1984). The lifespan of the red panda in the wild ranges from 8 to 10 years, whereas in captivity the average lifespan is 13.4 years (Heath and Platnick, 2008). There is no sexual dimorphism in the size and colour (Roberts and Gittleman, 1984).

Red panda forage primarily on the ground (Roberts and Gittleman, 1984) and is largely a vegetarian feeding mainly on bamboo leaves [80-90\%] (Roberts and Gittleman, 1984; Wei and Zhang, 2009). They also feed on insects, bamboo shoots, small vertebrates, birds, flowers, berries, eggs and seeds (Roberts and Gittleman, 1984; Srivastav et al., 2009; Wei and Zhang, 
2011). Bamboo leaves of the genera Thamnocalamus, Phyllostachys, Chimonobambusa, Sinarundinaria and Qiongzhuea form its main diet (Roberts and Gittleman, 1984; Nijboer and Dierenfeld, 2011).

This review outlines the normal anatomy of the red panda as a reference for clinical use and species identification.

\section{Anatomy}

\subsection{Musculoskeletal System}

The vertebral formula of the red panda is 7 cervical, 14 thoracic, 6 lumbar, 3 fused sacral and up to 19 caudal (coccygeal) vertebrae [C7, T14, L6, S3, Cd19] (Flower, 1870; Fisher 2011; Makungu et al., 2016; Makungu et al., 2018). However, it is uncommon to find red pandas with 15 thoracic and 5 lumbar vertebrae (Makungu, 2015). Further, 19 thoracolumbar vertebrae have been reported in a red panda with 14 thoracic and five lumbar vertebrae (Makungu, 2015). The spinous processes of the thoracolumbar vertebrae are short (Figure 2A) (Makungu et al., 2016; Makungu et al., 2018). The size of the thoracic vertebrae increase from cranial to caudal with the thoracic vertebra 11 (T11) frequently being an anticlinal vertebra and rarely T10 (Makungu et al., 2016). Lumbosacral transitional vertebra and the presence of two fused sacral segments have been reported in red pandas (Makungu et al., 2018). The number of ribs in red pandas is mainly 14 pairs which correspond to the number of thoracic vertebrae (Figure 2). Of the 14 pairs, the last two pairs are floating ribs (Figure 2) (Makungu et al., 2016). Pandas with 15 pairs of ribs, the last three pairs are floating (Makungu et al., 2016). The sternum is fairly straight and consists of the manubrium sterni, xiphoid process and six sternebrae (Figure 2A) (Makungu et al., 2016).

In heavy red pandas hypaxial muscles are easily seen on ventrodorsal radiographs of the abdomen (Makungu et al., 2018). Further, accumulation of large amount of abdominal fat is seen in the retroperitoneal space and ventral to the liver in heavy red pandas on right lateral abdominal radiographs (Makungu et al., 2018).

The scapula of the red panda is wide craniocaudally with a large hamate process (Figure 2) and stout coracoid process, which are indicative of its arboreality (Roberts and Gittleman, 1984; Makungu et al., 2015b). Rudimentary clavicles may be seen in some red pandas on radiographs of the shoulder joints (Makungu et al., 2015b; Makungu et al., 2016). The major tubercle of the humerus does not extend above the head of the humerus and the area for the insertion of the infraspinatus muscle is at the same level as the head of the humerus (Makungu et al., 2015b). The medial epicondyle, which provides the origin for the flexor muscles of the carpus and digits and the lateral supracondylar crest, which provides the origin for the brachioradialis muscle that supinates the antebrachium are prominent (Makungu et al., 2015b). The supracondylar foramen is present in red pandas and transmits the median nerve (Fisher, 2011). The radial tuberosity which provides the insertion of the biceps brachii muscle, a flexor of the elbow joint, is prominent and further distally located. Additionally, the head of the ulna is well-developed and stout (Makungu et al., 2015b).

The carpus of the red panda consists of seven carpal bones with the accessory carpal bone 


\section{Ml Macrothink}

Journal of Biology and Life Science ISSN 2157-6076 2019, Vol. 10, No. 1

being directed palmarolaterally (Makungu et al., 2015b). The sesamoid bone for the abductor digit I longus muscle, which abducts the carpal joint and carpometacarpal joint of digit $\mathrm{I}$ is relatively prominent and acts as a 'false thumb' for the grasping actions of the manus (Endo et al., 2001; Antón et al., 2006; Fisher et al., 2009; Makungu et al., 2015b). The pelvic bone has a wide ventromedial surface of the ilium. The ilial wings are almost parallel to each other and the ischiatic tuberosities are not prominent (Makungu et al., 2015a). The cranial and caudal ramus of the pubic bone are wide. Red pandas have a wide and shallow trochlea of the femur. The cochlea grooves of the tibia and the trochlea of the talus are shallow (Makungu et al., 2015a). Additionally, the lateral process of the base of the fifth metatarsal bone is directed laterally (Makungu et al., 2015a). The metacarpal and metatarsal bones are widely spaced (Makungu et al., 2015a, b).

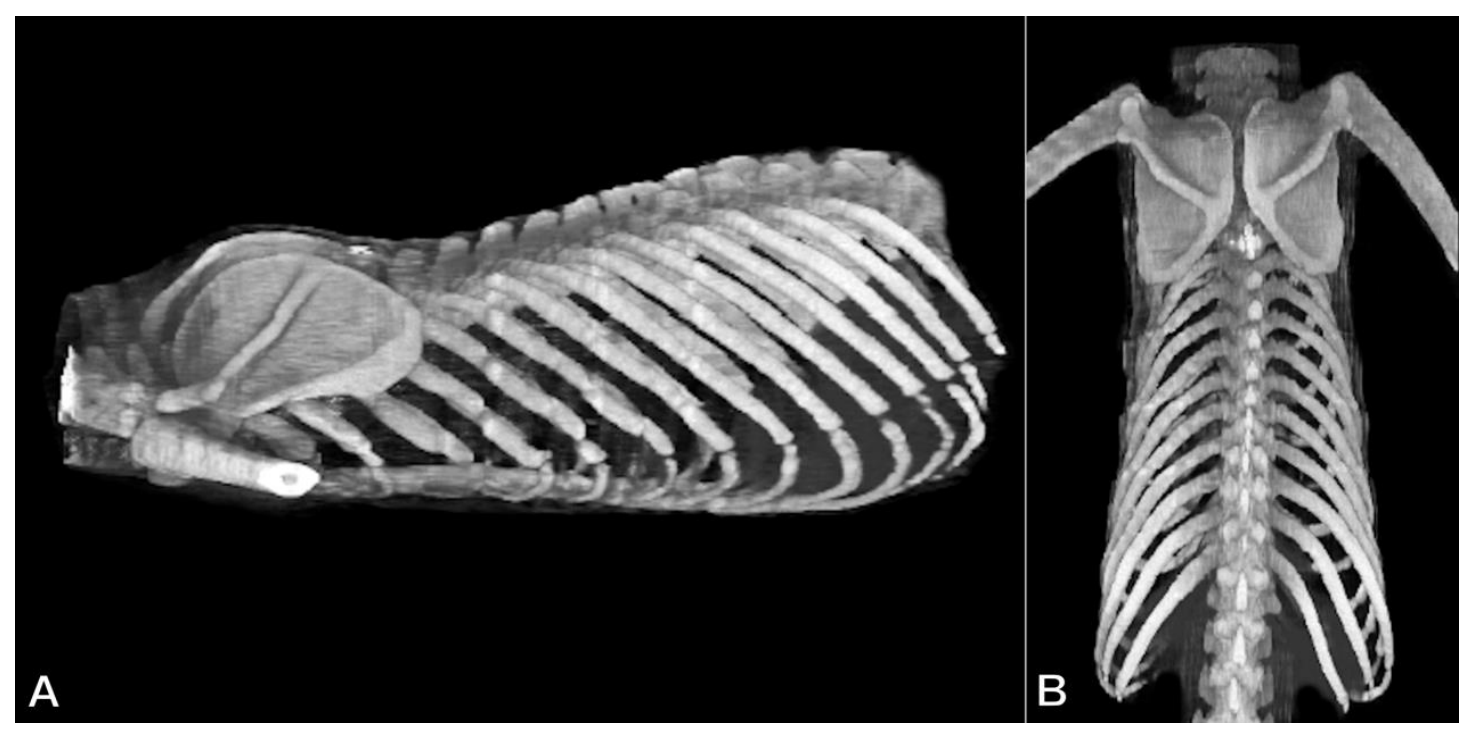

Figure 2 Lateral (A) and dorsal (B) views of a 3D volume-rendered computed tomography images (using a grey scale default) of the thorax of an adult red panda. The spinous processes of the thoracic vertebrae are relatively short. Note the wide scapula with large hamate process. Note also the presence of 14 pairs of ribs which correspond to the number of thoracic vertebrae. The last two pairs of ribs are floating and the sternum is fairly straight.

\subsection{Respiratory System}

The thyroid, cricoid, and arytenoid cartilages of the larynx in the red panda are reduced as seen in procyonids (Fisher, 2011). The thyroid and cricoid cartilages are very narrow dorsoventrally (Flower, 1870). The epiglottis is in the form of an equilateral triangle (Flower, 1870).

The trachea of the red panda is approximately $11.4 \mathrm{~cm}$ in length and $1.3 \mathrm{~cm}$ in average width (Flower, 1870). It consists of 38 cartilage rings, which are incompletely dorsally (Flower, 1870; Makungu, 2015). On thoracic radiographs, the trachea is seen with mineralized cartilage rings and its external diameter measures $1.35 \pm 0.13 \mathrm{~cm}$ in average (Makungu et al., 2016). On the dorsoventral radiographic view of the thorax, the trachea runs slightly to the right of the spine (Makungu et al., 2016). In majority of red pandas, the carina is located at the level of the fifth intercostal space (Makungu et al., 2016). The trachea branches into two 
short principal bronchi i.e. the right and left principal bronchi (Flower, 1870). The latter is slightly longer and narrower than the former (Flower, 1870). Each principal bronchus divides into cranial and caudal branches (Flower, 1870).

The left lung consists of two triangular lobes i.e. the cranial and caudal lobes (Flower, 1870; Makungu, 2015). The caudal lobe is slightly larger than the cranial lobe (Flower, 1870). The cranial lobe of the left lung is not subdivided into the cranial and caudal parts (Makungu, 2015). The right lung has four lobes namely; the cranial, middle, caudal and accessory lobes (Makungu, 2015). The accessory lobe is pointed and lies in the medial surface of the caudal lobe (Flower, 1870). The cranial branch of each principal bronchus is confined to the cranial branch of each lung (Flower, 1870; Makungu 2015). The caudal branch of the left principal bronchus is confined to the caudal lobe of the left lung, whereas, the caudal branch of the right principal bronchus also sends bronchial branches to the accessory and middle lobes (Flower, 1870; Makungu, 2015).

\subsection{Circulatory System}

The heart is shaped like a narrow cone with a rounded apex (Flower, 1870). It is approximately $5 \mathrm{~cm}$ in length with a thickness of $3.8 \mathrm{~cm}$ and $3.3 \mathrm{~cm}$ from side to side and cranial to caudal, respectively, (Flower, 1870). On thoracic radiographs the cardiac silhouette appears ovoid and oblique in position (Makungu et al., 2016). In older animals the cardiac silhouette and aortic arch are elongated with the former being more horizontally positioned (Makungu et al., 2016). The size of the cardiac silhouette with respect to vertebral heart score has been reported to be $8.34 \pm 0.25$ and $8.78 \pm 0.34$ on the right lateral and dorsoventral radiographs of the thorax, respectively, (Makungu et al., 2016). The pericardium is loaded with fat (Flower, 1870).

The elongated spleen is without a notch or fissure and is located on the left of the stomach (Flower, 1870). On the ventrodorsal radiographs of the abdomen, the spleen is seen lateral to the left kidney adjacent to the left body wall (Makungu et al., 2018). It is $14.5 \mathrm{~cm}$ long (Flower, 1870) with a mean thickness of $1.42 \pm 0.28 \mathrm{~cm}$ (Makungu et al., 2018).

The thymus, a lymphoid organ involved in the development of lymphocytes (Bezuidenhout $e t$ al., 2000) is very conspicuous (Flower, 1870). It is an oblong compressed body which lies cranial to the heart (Flower, 1870). The thymus measures approximately $3.8 \mathrm{~cm}$ in length and $1.3 \mathrm{~cm}$ in thickness (Flower, 1870).

\subsection{Digestive System}

The red panda has 36 to 38 teeth, with the following dental formula: I3/3, C1/1, PM3/3-4 and M2/2 (Roberts and Gittleman, 1984). The canines and incisors are characterized by low crown heights, whereas, the premolars and molars are distinguished by a number of accessory cusps (Fisher, 2011). The premolar cusps are rounded and low (Fisher, 2011). The upper fourth premolar is large with five cusps (Roberts and Gittleman, 1984). Additionally, the second and third upper and lower premolars are also large and robust (Roberts and Gittleman, 1984), with their width exceeding their length (Fisher, 2011). The large surface of cheek tooth facilitates mediolateral movement, which is important for effective grinding of bamboo and 
fibrous plant materials (Roberts and Gittleman, 1984; Fisher, 2011).

The tongue is approximately $7.6 \mathrm{~cm}$ in length from the base to the apex, with a maximum width of $2.8 \mathrm{~cm}$ (Flower, 1870). The caudal half of the tongue is thick and fleshy, and the dorsal surface is flat cranially (Flower, 1870). The mucosa on the dorsal surface forms five types of papillae namely; the conical, foliate, fungiform, filiformes and circumvallate papillae (Flower, 1870; Carlsson, 1925; Roberts and Gittleman, 1984; Fisher, 2011). The papillae are soft and small (Flower, 1870). The tonsils are approximately $0.6 \mathrm{~cm}$ in length and are very distinct (Flower, 1870). The salivary glands are relatively large as seen in most omnivorous carnivores (Carlsson, 1925). The parotid salivary gland duct opens into the oral cavity at the level of the third premolars (Flower, 1870). The ovoid mandibular salivary gland, which is smaller than the parotid salivary gland measures $2.5 \mathrm{~cm}$ in length with a greatest thickness of $1.3 \mathrm{~cm}$. Its duct terminates in an orifice at the sublingual caruncle (Flower, 1870).

The liver consists of four lobes; the left, quadrate, right and caudate lobes (Makungu, 2015). The left lobe is sub-divided into the left lateral and left medial lobes (Makungu, 2015). Similarly, the right lobe is also sub-divided into the right lateral and right medial lobes (Makungu, 2015). The caudate lobe has two processes i.e. the papillary and caudate processes. The caudate process of the caudate lobe presents with a renal fossa (Makungu, 2015). The gall bladder is situated between the right medial and quadrate lobes (Makungu, 2015). On ultrasonography, the mean wall thickness of the gall bladder has been reported to be $0.86 \pm$ $0.18 \mathrm{~mm}$ (Makungu, 2015).

The stomach consists of a single chamber (Flower, 1870). The thick walled pylorus is narrow and tubular, whereas, the fundus is large and spherical (Flower, 1870; Carlsson 1925; Roberts and Gittleman, 1984). The pylorus is frequently located to the right of the midline and cranially to the fundus on ventrodorsal radiographs of the abdomen (Makungu et al., 2018). The digestive tract is relatively short measuring 4.2 times the body length (Roberts and Gittleman, 1984). The length from the pylorus to the anus has been reported to be approximately $264.2 \mathrm{~cm}$ (Flower, 1870). The ascending, transverse and descending colons are relatively short and the colon and rectum measures $18 \mathrm{~cm}$ in length (Carlsson 1925). The caecum is absent and externally there is no clear distinction between the ileum and colon (Flower, 1870). The external diameter of the large intestine is approximately 2 times the external diameter of the small intestine (Makungu et al., 2018). Further, the mean external diameter of the small and large intestines measured on abdominal radiographs is $0.9 \pm 0.37$ $\mathrm{cm}$ and $1.8 \pm 0.22 \mathrm{~cm}$, respectively (Makungu et al., 2018). Bunching of small intestine in the right central abdomen has been observed in heavy red pandas (Makungu et al., 2018).

\subsection{Urogenital System}

The ovoid kidneys (Makungu, 2015) are not lobulated with the right kidney slightly more dorsal and cranial than the left kidney (Flower, 1870; Makungu et al., 2018). The right kidney is larger than the left kidney with a mean length and width of $3.98 \pm 0.33 \mathrm{~cm}$ and $2.19 \pm 0.24$ $\mathrm{cm}$, respectively (Makungu, 2015). The mean length and width of the left kidney are $3.85 \pm$ $0.27 \mathrm{~cm}$ and $2.16 \pm 0.19 \mathrm{~cm}$, respectively (Makungu, 2015). The red panda kidney is also prone to physiological accumulation of fat (Zwart et al., 1989). The oblong urinary bladder 
has a mean wall thickness of $1.46 \pm 0.36 \mathrm{~mm}$ (Makungu, 2015; Makungu et al., 2018). However, the thickness of the wall of the urinary bladder depends on the degree of bladder distension (Geisse et al., 1997).

The penis is relatively short and it is approximately $5 \mathrm{~cm}$ in length from the junction of the crura to the end of the glans (Flower, 1870; Roberts and Gittleman, 1984). The testes are approximately $2 \mathrm{~cm}$ long and $1.3 \mathrm{~cm}$ wide and appear like oval elevations under the skin (Flower, 1870; Carlsson 1925). The os penis is relatively short about $2 \mathrm{~cm}$ long (Flower, 1870; Roberts and Gittleman, 1984; Makungu et al., 2015a).

\section{Conclusion}

This review has provided information on the normal anatomy of the musculoskeletal, respiratory, circulatory, digestive and urogenital systems of the red panda. Although the red panda shares anatomical features with other members in the order Canivora, it possesses some unique anatomical features. Information obtained from this review will serve as guidance for clinical use and for identification of this species.

\section{References}

Antón, M., Salesa, M. J., Pastor, J. F., Peigné, S., \& Morales, J. (2006). Implication of the functional anatomy of the hand and fore arm of Ailurus fulgens (Carnivora, Ailuridae) for the evolution of the 'false thumb' in pandas. Journal of Anatomy, 209(6), 757-764. https://doi.org/10.1111/j.1469-7580.2006.00649.x

Bezuidenhout, A. J., Groenewald, H. B., Hornsveld, M., Soley, J. T., \& Turner, P. H. (2000). Veterinary anatomy: a study and dissection guide. Pretoria: University of Pretoria.

Carlsson, A. (1925). Über Ailurus fulgens (About Ailurus fulgens). Acta Zoologica, 6(1-2). 269-305. https://doi.org/10.1111/j.1463-6395.1925.tb00268.x

Endo, H., Sasaki, M., Kogiku, H., Yamamoto, M., \& Arishima, K. (2001). Radial sesamoid bone as a part of the manipulation system in the lesser panda (Ailurus fulgens). Annals of Anatomy, 183, 181-184. https://dx.doi.org/10.1016/50940-9602(01)80045-5

Eriksson, P., Zidar, J., White, D., Westander, J., \& Andersson, M. (2010). Current husbandry of red pandas (Ailurus fulgens) in zoos. Zoo Biology, 29(6), 732-740.

https://doi.org/10.1002/zoo.20323

Fisher, R. E. (2011). Red panda anatomy. In A. R. Glatston (Ed.), Red Panda Biology and Conservation of the First Panda (pp. 89-100). London: Academic Press. https://doi.org/10.1016/B978-1-4377-7813-7.00006-9

Fisher, R. E., Adrian, B., Barton, M., Holmgren, J., \& Tang, S. Y. (2009). The phylogeny of the red panda (Ailurus fulgens) evidence from the forelimb. Journal of Anatomy, 215(6), 611-635. https://doi.org/10.1111/j.1469-7580.2009.01156.x

Flower, W. H. (1870). On the anatomy of Ailurus fulgens. Journal of Zoology, 38(1), 752-769. https://doi.org/10.1111/j.1469-7998.1870.tb00466.x 
Geisse, A. L., Lowry, J. E., Schaeffer, D. J., \& Smith, C. W. (1997). Sonographic evaluation of urinary bladder wall thickness in normal dogs. Veterinary Radiology and Ultrasound, 38(2), 132-137. https://doi.org/10.1111/j.1740-8261.1997.tb00828.x

Ghose, D., \& Dutta, P. K. (2011). Status and distribution of red panda Ailurus fulgens fulgens in India. In A. R. Glatston (Ed.), Red Panda Biology and Conservation of the First Panda (pp. 357-373). London: Academic Press. https://doi.org/10.1016/B978-1-4377-7813-7.00020-3

Groves, C. (2011). The taxonomy and phylogeny of Ailurus. In A. R. Glatston (Ed.), Red Panda Biology and Conservation of the First Panda (pp. 101-124). London: Academic Press. https://doi.org/10.1016/B978-1-4377-7813-7.00007-0

Heath, T., \& Platnick, J. (2008). “Ailurus fulgens”. Animal Diversity Web [Online] Available: http://animaldiversity.org/accounts/Ailurus_fulgens/ (August 16, 2018).

IUCN, (2018). IUCN red list of threatened species. Version 2018.1. [Online] Available: www.iucnredlist.org (August 14, 2018).

Makungu, M. (2015). Aspects of the morphological, radiographic and ultrasonographic anatomy of the red panda (Ailurus fulgens) and ring-tailed lemur (Lemur catta). A thesis submitted in partial fulfilment of the requirements for the degree of Doctor of Philosophy in the Department of Anatomy and Physiology in the Faculty of Veterinary Science, University of Pretoria. Pretoria: University of Pretoria.

Makungu, M., du Plessis, W. M., Barrows, M., Groenewald, H. B., \& Koeppel, K. N. (2016). Radiographic thoracic anatomy of the red panda (Ailurus fulgens). Journal of Zoo and Wildlife Medicine, 47(3), 781-789. https://doi.org/10.1638/2016-0004.1

Makungu, M., du Plessis, W. M., Barrows, M., Groenewald, H. B., \& Koeppel, K. N. (2018). Radiographic abdominal anatomy in captive red pandas (Ailurus fulgens). Journal of Zoo and Wildlife Medicine, 49(1), 214-218. https://doi.org/10.1638/2016-0167R2.1

Makungu, M., du Plessis, W. M., Groenewald, H. B., Barrows, M., \& Koeppel, K. N. (2015a). Morphology of the pelvis and hind limb of the red panda (Ailurus fulgens) evidenced by gross osteology, radiography and computed tomography. Anatomia Histologia Embryologia, 44(6), 410-421. https://doi.org/10.1111/ahe.12152

Makungu, M., Groenewald, H. B., du Plessis, W. M., Barrows, M., \& Koeppel, K. N. (2015b). Thoracic limb morphology of the red panda (Ailurus fugens) evidenced by osteology and radiography. Onderstepoort Journal of Veterinary Research, 82(1), 953.

https://doi.org/10.4102/ojvr.v82i1.953

Nijboer, J., \& Dierenfeld, E. S. (2011). Red panda nutrition: how to feed a vegetarian carnivore. In A. R. Glatston (Ed.), Red Panda Biology and Conservation of the First Panda (pp. 257-270). London: Academic Press.

Pradhan, S., Saha, G. K., \& Khan, J. A. (2001). Ecology of the red panda Ailurus fulgens in the Singhalila National Park, Darjeeling, India. Biological Conservation, 98(1), 11-18. https://doi.org/10.1016/S0006-3207(00)00079-3 


\section{Macrothink}

Preece, B. (2011). Red panda pathology. In A. R. Glatston (Ed.), Red Panda Biology and Conservation of the First Panda (pp. 287-302). London: Academic Press. https://doi.org/10.1016/B978-1-4377-7813-7.00016-1

Roberts, M. S., \& Gittleman, J. L. (1984). Ailurus fulgens. Mammalian Species, 222, 1-8. https://doi.org/10.2307/3503840

Srivastav, A., Nigam, P., Chakraborty, D., \& Nayak, A. K. (2009). The National Studbook of Red Panda (Ailurus fulgens). New Delhi: Wildlife Institute of India, Dehradun and Central Zoo Authority.

Wei, F., \& Zhang, Z. (2009). Family Ailuridae (red panda). In D. E. Wilson, \& R. A. Mittermeier (Eds.), Handbook of the Mammals of the World vol 1 Carnivores (pp. 498-503). Barcelona: Lynx Edicions.

Wei, F., \& Zhang, Z. (2011). Red panda ecology. In A. R. Glatston (Ed.), Red Panda Biology and Conservation of the First Panda (pp. 193-212). London: Academic Press. https://doi.org/10.1016/B978-1-4377-7813-7.00011-2

Zwart, P. C. (1989). Contribution to the pathology of the red panda (Ailurus fulgens). In A. R. Glatston (Ed.), Red panda biology (pp. 25-29). The Netherlands: SPB Academic Publishing.

\section{Copyright Disclaimer}

Copyright for this article is retained by the author(s), with first publication rights granted to the journal.

This is an open-access article distributed under the terms and conditions of the Creative Commons Attribution license (http://creativecommons.org/licenses/by/3.0/). 